\title{
Incidence rates and contemporary trends in primary urethral cancer
}

\author{
Mike Wenzel ${ }^{1,2} \mathbb{D} \cdot$ Luigi Nocera ${ }^{2,3} \cdot$ Claudia Collà Ruvolo $^{2,4} \cdot$ Christoph Würnschimmel $^{2,5} \cdot$ Zhe Tian $^{2}$. \\ Shahrokh F. Shariat ${ }^{6,7,8,9,10,11}$. Fred Saad ${ }^{2}$. Alberto Briganti ${ }^{4}$. Derya Tilki ${ }^{5}$. Philipp Mandel ${ }^{1}$. Andreas Becker ${ }^{1}$. \\ Luis A. Kluth ${ }^{1}$. Felix K. H. Chun ${ }^{1}$. Pierre I. Karakiewicz ${ }^{2}$
}

Received: 11 November 2020 / Accepted: 9 March 2021 / Published online: 22 March 2021

(c) The Author(s) 2021

\begin{abstract}
Purpose We assessed contemporary incidence rates and trends of primary urethral cancer.

Methods We identified urethral cancer patients within Surveillance, Epidemiology and End Results registry (SEER, 20042016). Age-standardized incidence rates per 1,000,000 (ASR) were calculated. Log linear regression analyses were used to compute average annual percent change (AAPC).

Results From 2004 to 2016, 1907 patients with urethral cancer were diagnosed (ASR 1.69; AAPC: -0.98\%, $p=0.3$ ). ASR rates were higher in males than in females ( 2.70 vs. 0.55 ), respectively and did not change over the time (both $p=0.3)$. Highest incidence rates were recorded in respectively $\geq 75(0.77), 55-74(0.71)$ and $\leq 54(0.19)$ years of age categories, in that order. African Americans exhibited highest incidence rate (3.33) followed by Caucasians (1.72), other race groups (1.57) and Hispanics (1.57), in that order. A significant decrease occurred over time in Hispanics, but not in other race groups. In African Americans, male and female sex-stratified incidence rates were higher than in any other race group. Urothelial histological subtype exhibited highest incidence rate (0.92), followed by squamous cell carcinoma (0.41), adenocarcinoma $(0.29)$ and other histologies (0.20). In stage stratified analyses, $\mathrm{T}_{1} \mathrm{~N}_{0} \mathrm{M}_{0}$ stage exhibited highest incidence rate. However, it decreased over time $(-3.00 \%, p=0.02)$ in favor of $\mathrm{T}_{1-4} \mathrm{~N}_{1-2} \mathrm{M}_{0}$ stage $(+2.11 \%, p=0.02)$.

Conclusion Urethral cancer is rare. Its incidence rates are highest in males, elderly patients, African Americans and in urothelial histological subtype. Most urethral cancer cases are $T_{1} N_{0} M_{0}$, but over time, the incidence of $T_{1} N_{0} M_{0}$ decreased in favor of $\mathrm{T}_{1-4} \mathrm{~N}_{1-2} \mathrm{M}_{0}$.
\end{abstract}

Keywords Urethral cancer $\cdot$ Incidence rate $\cdot$ Time trend $\cdot$ Region $\cdot$ Race $\cdot$ Histology

Mike Wenzel

Mike.Wenzel@kgu.de

1 Department of Urology, University Hospital Frankfurt, Theodor- Stern Kai 7, 60590 Frankfurt am Main, Germany

2 Cancer Prognostics and Health Outcomes Unit, Division of Urology, University of Montréal Health Center, Montréal, Québec, Canada

3 Department of Urology and Division of Experimental Oncology, URI, Urological Research Institute, IBCAS San Raffaele Scientific Institute, Milan, Italy

4 Department of Neurosciences, Reproductive Sciences and Odontostomatology, University of Naples Federico II, Naples, Italy

5 Martini-Klinik Prostate Cancer Center, University Hospital Hamburg-Eppendorf, Hamburg, Germany
6 Department of Urology, Comprehensive Cancer Center, Medical University of Vienna, Vienna, Austria

7 Departments of Urology, Weill Cornell Medical College, New York, NY, USA

8 Department of Urology, University of Texas Southwestern, Dallas, TX, USA

9 Department of Urology, Second Faculty of Medicine, Charles University, Prag, Czech Republic

10 Institute for Urology and Reproductive Health, I.M. Sechenov First Moscow State Medical University, Moscow, Russia

11 Division of Urology, Department of Special Surgery, Jordan University Hospital, The University of Jordan, Amman, Jordan 


\section{Introduction}

Primary urethral cancer is extremely rare [1-4]. Risk factors for primary urethral cancer are for example recurrent urinary tract infections, chronic irritation through catheterization or sexual transmitted diseases [5-7]. Treatment of urethral cancer depends on its stage at presentation. Usually, surgical treatment is recommended, but also radiation therapy can be applied for organ preservation. In metastatic disease, chemotherapy is recommended ${ }^{2}$. While primary urethral cancer originates from the urethra itself, secondary urethral cancer can be caused by a metastatic spread.

In a study by Swartz et al., relying on 1615 patients with primary urethral cancer identified between 1973 and 2002, urethral cancer annual age adjusted incidence rates were respectively 4.3 and 1.5 per million for men and women in the United States. Moreover, important differences between urethral cancer incidence rates have been investigated in this study with regard to race/ethnicity, age groups, histological subtype and regions [1]. However, urethral cancer incidence rates according to patient and tumor characteristics have not been reassessed since 2002 . To test for differences in incidence rates in different patient and tumor characteristic groups across all urethral cancer patients is particularly important, since differences exist within those groups $[8,9]$. For example, the most frequent histological subtype in males is urothelial vs. adenocarcinoma in female urethral cancer patients [8]. Moreover, differences also exist between racial/ethnic urethral cancer groups $[8,10]$.

We addressed these knowledge gap and hypothesized that significant differences in incidence rate of urethral cancer and its trends over time may exist.

\section{Material and methods}

\section{Study population}

In the current study we relied on the Surveillance, Epidemiology and End Results registry (SEER) database (2004-2016) to reassess incidence rates regarding different patient cohorts in primary urethral cancer. The current SEER database samples $34.6 \%$ of the United States (US) population and approximates it in demographic composition and cancer incidence [11]. Within the SEER database (2004-2016), we identified patients $\geq 18$ years old with histologically confirmed primary urethral cancer (International Classification of Disease for Oncology [ICD-O] site code C68.0). WHO classification was used to define histological subtypes as either urothelial vs. squamous cell carcinoma (SCC), adenocarcinoma or other histology [12]. TNM-stage was used according to the 8th edition of malignant tumors [13]. Race groups were defined as Caucasian vs. African American vs. Hispanic or other race group. Regions were grouped due to low incidence rates and cases within each SEER registries: West (Registries Los Angeles, New Mexico, San-Jose-Monterey, Seattle, California, San Francisco-Oakland, Utah, Alaska, Hawaii) vs. Midwest (Registries Detroit and Iowa) vs. North-East (Registries Connecticut and New Jersey) vs. South (Registries Atlanta, Louisiana, Rural Georgia, Greater Georgia, Kentucky). According to the age stratification by Swartz et al., three modified age categories were defined, namely patients $\leq 54$ years, patients $55-74$ years and patients $\geq 75$ years [1]. Unknown histology and unknown racial status patients were excluded. Urethral cancers identified only according to death certificate or at autopsy were also excluded. These selection criteria yielded 1907 assessable urethral cancer patients.

\section{Statistical analysis}

Age-adjusted incidence rates per 1,000,000 based on US year 2000 standard population were calculated (19 age groups, US Bureau of the Census, Current Population Reports, Publication 25-110 [Census P25-1130]) and defined as agestandardized rates (ASR). The latter represented weighted averages of age-specific rates, where weights corresponded to proportions of persons in each-age group of a standard population. Log linear regressions were used to compute average annual percent change (AAPC). Absolute annual cases of newly diagnosed urethral cancer cases in the US were calculated, assuming SEER database is representative of the US population, with calculated incidence rate per specific year multiplied with US population in the corresponding year. All tests were two sided with a level of significance set at $p<0.05$ and $\mathrm{R}$ software environment for statistical computing and graphics (version 3.4.3) was used for all analyses.

\section{Results}

From 2004 to 2016, 1907 newly diagnosed primary urethral cancers were recorded (Table 1). The overall ASR was $1.69 / 1,000,000$ according to US year 2000 standard population and did not change over the time (AAPC: $-0.98 \% ; p=0.3$; Fig. 1a). After stratification according to patient sex, overall ASR was higher in males than in females $(2.70$ vs. $0.55 / 1,000,000)$. In temporal trend analyses according to patient sex, ASR in males and females did not change over the time (AAPC: $-0.98 \%, p=0.3$ vs. 
Table 1 Age-standardized incidence rates of urethral cancer

\begin{tabular}{|c|c|c|c|c|c|c|}
\hline & \multirow[b]{2}{*}{ No of patients (\%) } & \multicolumn{3}{|c|}{$\begin{array}{l}\text { Age-adjusted incidence } \\
\text { rate/1,000,000 US year } 2000 \\
\text { standard population }\end{array}$} & \multicolumn{2}{|c|}{ Time trend } \\
\hline & & Overall & 2004 & 2016 & AAPC & $P$ value \\
\hline Overall & $1907(100)$ & 1.69 & 1.70 & 1.63 & $-0.98 \%$ & 0.3 \\
\hline \multicolumn{7}{|l|}{ Patient sex } \\
\hline Male & $1302(68.3)$ & 2.70 & 2.64 & 2.53 & $-0.98 \%$ & 0.3 \\
\hline Female & $605(31.7)$ & 0.55 & 0.61 & 0.57 & $-1.82 \%$ & 0.19 \\
\hline \multicolumn{7}{|l|}{ Race } \\
\hline Caucasian & $1356(71.1)$ & 1.72 & 1.71 & 1.69 & $-0.32 \%$ & 0.7 \\
\hline African American & $312(16.4)$ & 3.33 & 3.01 & 2.49 & $-1.90 \%$ & 0.4 \\
\hline Hispanic & $134(7.0)$ & 1.57 & 1.59 & 1.31 & $-3.33 \%$ & 0.066 \\
\hline Other & $105(5.5)$ & 1.63 & 2.03 & 1.64 & $-2.81 \%$ & 0.01 \\
\hline \multicolumn{7}{|l|}{ Male race } \\
\hline Caucasian & $1007(77.3)$ & 2.97 & 2.99 & 2.83 & $-0.35 \%$ & 0.7 \\
\hline African American & $158(12.1)$ & 5.33 & 4.45 & 4.34 & $-1.86 \%$ & 0.2 \\
\hline Hispanic & $82(6.3)$ & 2.90 & 3.53 & 1.81 & $-5.96 \%$ & $<0.01$ \\
\hline Other & $55(4.2)$ & - & - & - & - & - \\
\hline \multicolumn{7}{|l|}{ Female race } \\
\hline Caucasian & $349(57.7)$ & 0.92 & 0.89 & 1.03 & $-0.65 \%$ & 0.6 \\
\hline African American & $154(25.5)$ & 3.15 & 3.62 & 2.37 & $-2.12 \%$ & 0.3 \\
\hline Hispanic & $52(8.6)$ & - & - & - & - & - \\
\hline Other & $50(8.2)$ & - & - & - & - & - \\
\hline \multicolumn{7}{|l|}{ Histology } \\
\hline Urothelial & 1009 (52.9) & 0.94 & 0.97 & 0.82 & $-1.49 \%$ & 0.14 \\
\hline $\mathrm{SCC}$ & $455(23.9)$ & 0.41 & 0.29 & 0.49 & $+0.34 \%$ & 0.8 \\
\hline Adenocarcinoma & $278(14.6)$ & 0.29 & 9.31 & 0.24 & $-0.48 \%$ & 0.7 \\
\hline Other & $165(8.7)$ & 0.20 & 0.24 & 0.26 & $-0.13 \%$ & 0.9 \\
\hline \multicolumn{7}{|l|}{ Male histology } \\
\hline Urothelial & $835(64.1)$ & 1.85 & 2.01 & 1.57 & $-1.99 \%$ & 0.10 \\
\hline $\mathrm{SCC}$ & $306(23.5)$ & 0.66 & 0.54 & 0.82 & $+0.62 \%$ & 0.7 \\
\hline Adenocarcinoma & $112(8.6)$ & 0.38 & 0.31 & 0.37 & $-0.19 \%$ & 0.9 \\
\hline Other & $49(3.8)$ & - & - & - & - & - \\
\hline \multicolumn{7}{|l|}{ Female histology } \\
\hline Urothelial & $174(28.8)$ & 0.36 & 0.34 & 0.23 & $-0.89 \%$ & 0.3 \\
\hline SCC & 149 (24.6) & 0.36 & 0.28 & 0.34 & $-1.20 \%$ & 0.3 \\
\hline Adenocarcinoma & $166(27.4)$ & 0.36 & 0.46 & 0.29 & $-1.39 \%$ & 0.3 \\
\hline Other & $116(19.1)$ & 0.27 & 0.31 & 0.37 & $-0.90 \%$ & 0.6 \\
\hline \multicolumn{7}{|l|}{ Stage } \\
\hline T1N0M0 & $596(31.3)$ & 0.57 & 0.66 & 0.39 & $-3.00 \%$ & 0.02 \\
\hline T2N0M0 & $133(7.0)$ & 0.18 & 0.14 & 0.34 & $+1.96 \%$ & 0.4 \\
\hline T3-4N0M0 & $516(27.1)$ & 0.48 & 0.52 & 0.31 & $-1.56 \%$ & 0.14 \\
\hline T1-4N1-2M0 & $252(13.2)$ & 0.26 & 0.23 & 0.30 & $+2.11 \%$ & 0.02 \\
\hline T1-4N0-2M1 & $181(9.5)$ & 0.22 & 0.19 & 0.19 & $-0.47 \%$ & 0.8 \\
\hline Unknown & $229(12.0)$ & - & - & - & - & - \\
\hline \multicolumn{7}{|l|}{ Male stage } \\
\hline T1N0M0 & 429 (32.9) & 1.00 & 1.14 & 0.61 & $-3.15 \%$ & 0.059 \\
\hline T2N0M0 & $100(7.7)$ & 0.33 & 0.27 & 0.62 & $+1.76 \%$ & 0.5 \\
\hline T3-4N0M0 & 347 (26.7) & 0.78 & 0.69 & 0.44 & $-1.49 \%$ & 0.3 \\
\hline T1-4N1-2M0 & $160(12.3)$ & 0.44 & 0.48 & 0.51 & $+1.26 \%$ & 0.15 \\
\hline T1-4N0-2M1 & $117(9.0)$ & 0.40 & 0.37 & 0.36 & $-0.91 \%$ & 0.5 \\
\hline Unknown & $149(11.4)$ & - & - & - & - & - \\
\hline
\end{tabular}


$-1.82 \%, p=0.19$; Fig. 1b). In analyses stratified according to patient age, highest ASR was recorded in $\geq 75$ years group (overall ASR: 0.77/1,000,000), followed by 55-74 years (overall ASR: 0.71/1,000,000) and $<54$ years in that order (overall ASR: 0.19/1,000,000). Absolute numbers of newly diagnosed urethral cancer cases were 436-622 new cases per year between 2004 and 2016 in the US (Table 2).

Table 1 (continued)

\begin{tabular}{|c|c|c|c|c|c|c|}
\hline & \multirow[b]{2}{*}{ No of patients (\%) } & \multicolumn{3}{|c|}{$\begin{array}{l}\text { Age-adjusted incidence } \\
\text { rate/1,000,000 US year } 2000 \\
\text { standard population }\end{array}$} & \multicolumn{2}{|c|}{ Time trend } \\
\hline & & Overall & 2004 & 2016 & AAPC & $P$ value \\
\hline \multicolumn{7}{|l|}{ Age groups } \\
\hline$\leq 54$ years & $228(12.0)$ & 0.19 & 0.28 & 0.10 & $-3.56 \%$ & 0.11 \\
\hline $55-74$ years & $802(42.1)$ & 0.71 & 0.67 & 0.77 & $+0.21 \%$ & 0.9 \\
\hline$\geq 75$ years & $877(46.0)$ & 0.77 & 0.70 & 0.74 & $-1.27 \%$ & 0.3 \\
\hline \multicolumn{7}{|l|}{ Region } \\
\hline Midwest & 205 (10.7) & 2.31 & 2.39 & 1.94 & $-4.10 \%$ & 0.03 \\
\hline Northeast & $320(16.8)$ & 2.10 & 2.07 & 1.53 & $-2.96 \%$ & 0.02 \\
\hline South & $481(25.2)$ & 1.99 & 1.90 & 1.88 & $+1.77 \%$ & 0.4 \\
\hline West & $901(47.2)$ & 1.50 & 1.44 & 1.75 & $+0.02 \%$ & 1 \\
\hline
\end{tabular}

Age-standardized incidence rates of urethral cancer and corresponding overall annual percentage changes in 1907 patients, identified within the Surveillance, Epidemiology, and End Results database from 2004 to 2016. Abbreviations: AAPC average annual percentage changes, US United States, SCC Squamous cell carcinoma

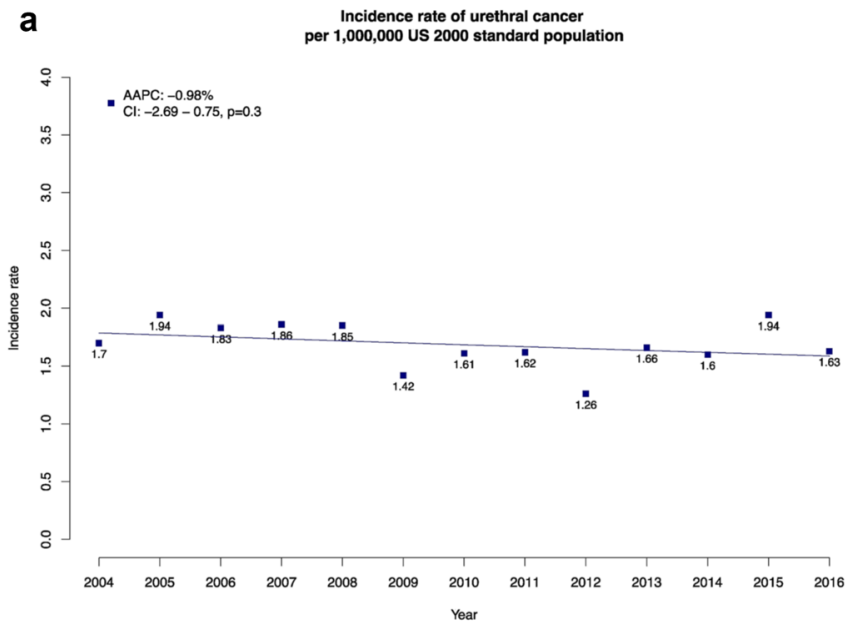

Fig. 1 Incidence and trends over time in urethral cancer in the United States. Incidence and trends over time in urethral cancer in the United States from 2004 to 2016, in the entire cohort (a) and according to

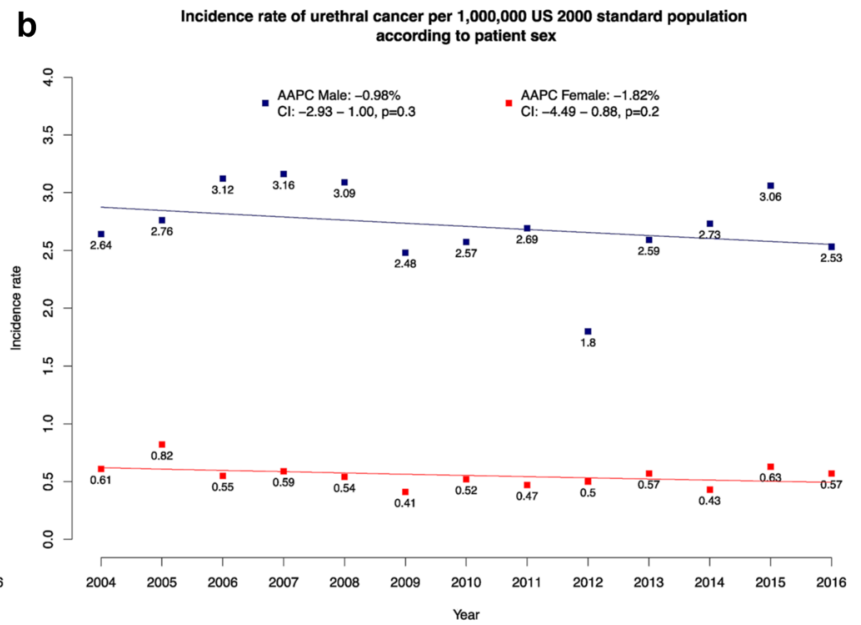

patient sex (b). Abbreviations: $A A P C$ Average annual percentage changes, $C I$ Confidence interval

Table 2 Urethral cancer cases in the United States between 2004 and 2016

\begin{tabular}{|c|c|c|c|c|c|c|c|c|c|c|c|c|c|}
\hline & 2004 & 2005 & 2006 & 2007 & 2008 & 2009 & 2010 & 2011 & 2012 & 2013 & 2014 & 2015 & 2016 \\
\hline Urethral cancer cases per year in the US & 498 & 573 & 546 & 559 & 564 & 436 & 499 & 504 & 397 & 525 & 508 & 622 & 527 \\
\hline
\end{tabular}

Absolute cases of urethral cancer patients per year in the United States (US) during 2004-2016, identified within the Surveillance, Epidemiology, and End Results database and calculated with the incidence rate per 1,000,000 US year 2000 standard population 


\section{The effect of race on ASR}

After stratification according to race groups, ASR was highest in African Americans (overall ASR: 3.33/1,000,000), followed by Caucasians (overall ASR: 1.69/1,000,000), other race groups (overall ASR: 1.63/1,000,000) and Hispanics (overall ASR: $1.57 / 1,000,000$ ). In temporal trend analyses according to race groups, ASR only decreased in other racial group (AAPC: $-2.81 \% ; p=0.01$ ).

After further stratification according to patient sex (Fig. 2a-b), African American males (overall ASR: $5.33 / 1,000,000)$ exhibited highest ASR, followed by Caucasians (overall ASR: 1.97/1,000,000) and Hispanics (average ASR: 2.90/1,000,000). In temporal trend analyses, incidence rate of Hispanic males decreased significantly over time (AAPC: $-5.96 \%, p<0.01$ ). In females, African Americans (overall ASR: 3.15/1,000,000) also exhibited higher ASR compared to Caucasians (overall ASR: 0.92/1,000,000). In temporal trend analyses in females that were stratified according to race, no differences were recorded. Due to sample size limitations, ASR could not be computed for other race group in either males or females. Similarly, sample size limitations prevented computation of ASR Hispanic females.

\section{Effect of histological subtype on ASR}

After stratification according to histological subtype, highest ASR was recorded in urothelial histology patients (overall ASR: 0.94/1,000,000), followed by SCC (overall ASR: 0.41/1,000,000), adenocarcinoma (overall ASR: $0.29 / 1,000,000$ ) and other histology subtype (overall ASR: $0.20 / 1,000,000)$.
After further stratification according to patient sex (Fig. 3a-b), in males ASR rates were respectively $1.85 / 1,000,000,0.66 / 1,000,000,0.38 / 1,000,000$ and $0.27 / 1,000,000$ for urothelial, SCC, adenocarcinoma and other histological subtype. Conversely in females, ASR rates were respectively $0.36 / 1,000,000,0.36 / 1,000,000$ and $0.36 / 1,000,000$ for urothelial, SCC and adenocarcinoma.

In temporal trend analyses, no clinically meaningful differences were recorded for each of examined histological subtype, with or without further stratification according to patient sex. Due to sample size limitations, ASR could not be computed for males with other histological subtype.

\section{Effect of region on ASR}

After stratification according to SEER regions, highest ASR was recorded in the Midwest $(2.31 / 1,000,000)$, followed by Northeast $(2.10 / 1,000,000)$, South $(1.99 / 1,000,000)$ and West $(1.50 / 1,000,000)$.

In temporal trend analyses, ASR decreased in the Midwest (AAPC: $-4.10 \% ; p=0.03$ ) and Northeast (AAPC: $-2.96 \% ; p=0.02$ ). Due to sample size limitations, ASR regional stratification could not be computed according to patient sex.

\section{Effect of stage at presentation on ASR}

After stratification according to stage at presentation (Fig. 4b-c), highest ASR was recorded in $\mathrm{T}_{1} \mathrm{~N}_{0} \mathrm{M}_{0}$ stage (overall ASR: $0.57 / 1,000,000$ ), followed by $\mathrm{T}_{3-4} \mathrm{~N}_{0} \mathrm{M}_{0}$ (overall ASR: 0.48/1,000,000), $\mathrm{T}_{1-4} \mathrm{~N}_{1-2} \mathrm{M}_{0}$ (overall ASR: 0.26/1,000,000), $\mathrm{T}_{1-4} \mathrm{~N}_{0-2} \mathrm{M}_{1}$ (overall ASR: 0.19/1,000,000) and $\mathrm{T}_{2} \mathrm{~N}_{0} \mathrm{M}_{0}$

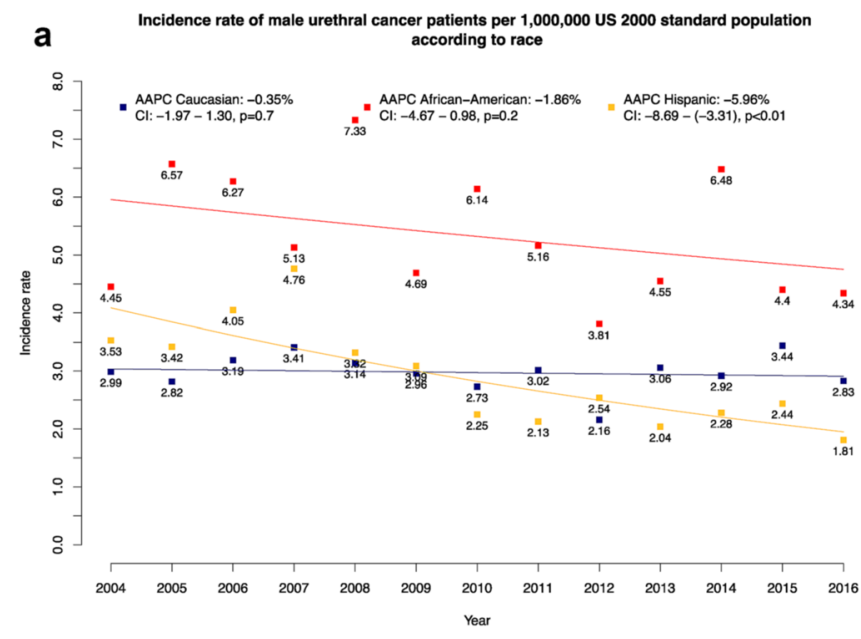

Fig. 2 Incidence and trends over time in urethral cancer in the United States from 2004 to 2016, according to race groups and sex for (a) male, (b) female. Due to sample size limitations, ASR could not be computed for other race group in either males or females. Simi-

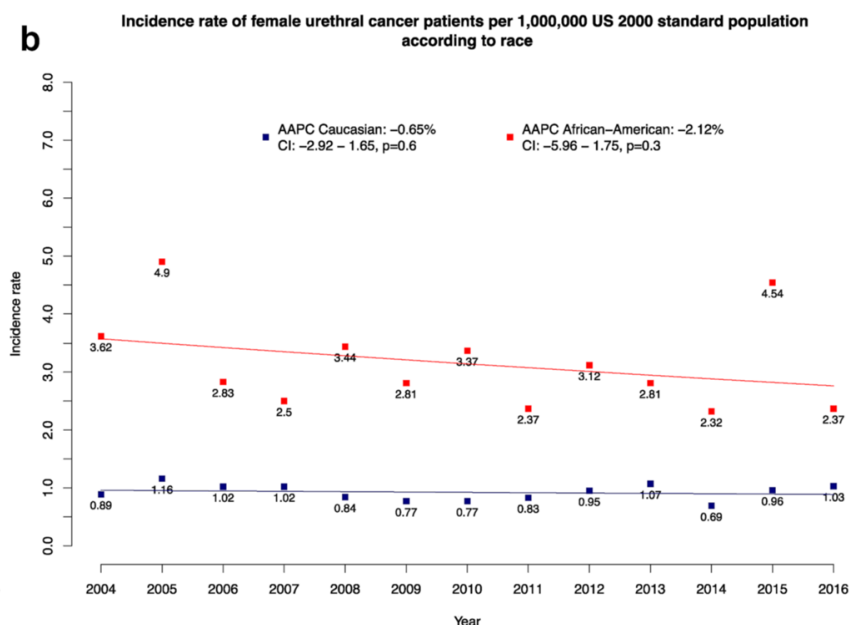

larly, sample size limitations prevented computation of incidence of Hispanic females. Abbreviations: AAPC Average annual percentage changes, $\mathrm{CI}$ Confidence interval 


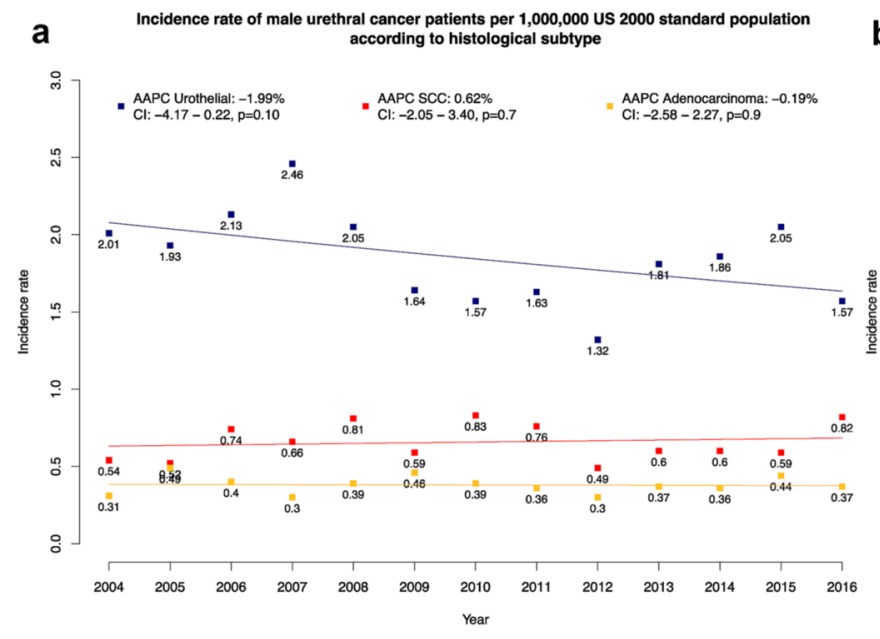

Fig. 3 Incidence and trends over time in urethral cancer in the United States from 2004 to 2016, according to histological subtype and sex Male (a), female (b). Due to sample size limitations, incidence could

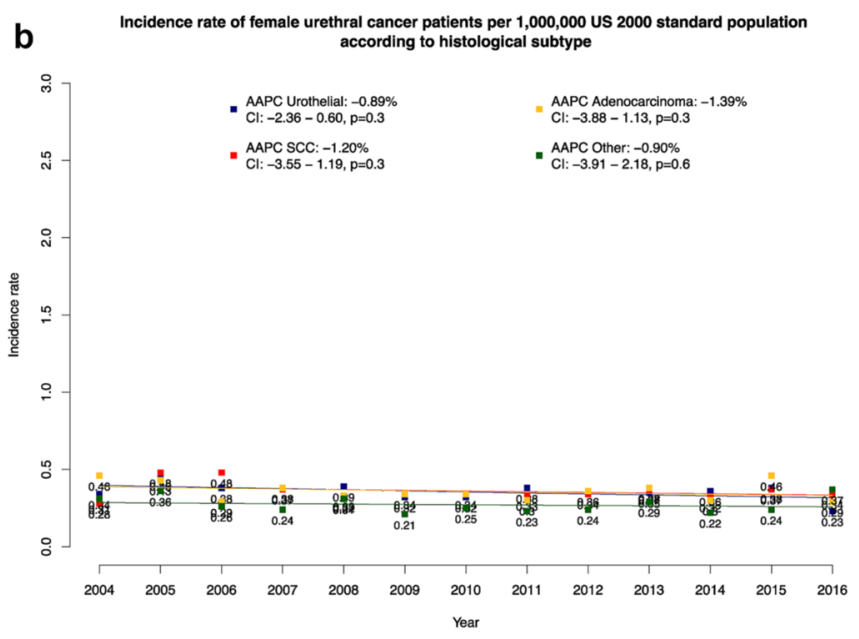

not be computed for males with other histological subtype. Abbreviations: $A A P C$ Average annual percentage changes, $C I$ Confidence interval, SCC Squamous cell carcinoma

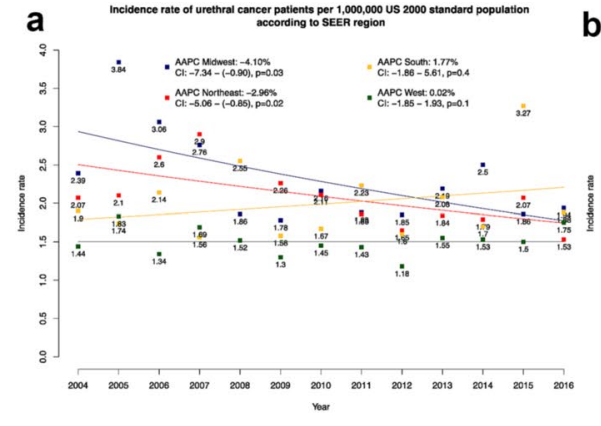

Fig. 4 Incidence and trends over time in urethral cancer in the United States from 2004 to 2016, according to SEER region (a) and stage at presentation (b), as well as stage at presentation in males (c) Due to sample size limitations, stratification of regional incidence rates could not be computed according to patient sex, as well as for stage at presentation in females. Abbreviations: $A A P C$ Average annual percentage changes, $\mathrm{CI}$ Confidence interval (overall ASR: 0.18/1,000,000), in that order. After further stratification according to male sex, ASR rates were respectively recorded 1.00 vs. 0.33 vs. 0.78 vs. 0.44 vs. 0.40 per $1,000,000$ for $\mathrm{T}_{1} \mathrm{~N}_{0} \mathrm{M}_{0}, \mathrm{~T}_{2} \mathrm{~N}_{0} \mathrm{M}_{0}, \mathrm{~T}_{3-4} \mathrm{~N}_{0} \mathrm{M}_{0}, \mathrm{~T}_{1-4} \mathrm{~N}_{1-2} \mathrm{M}_{0}$ and $\mathrm{T}_{1-4} \mathrm{~N}_{0-2} \mathrm{M}_{1}$, respectively. In temporal trend analyses, $\mathrm{T}_{1} \mathrm{~N}_{0} \mathrm{M}_{0}$ stage decreased (AAPC: $-3.00 \% ; p=0.02$ ) and $\mathrm{T}_{1-4} \mathrm{~N}_{1-2} \mathrm{M}_{0}$ stage increased over time (AAPC: $+2.11 \% ; p=0.03$ ). In temporal trend analyses according to male sex, $\mathrm{T}_{1} \mathrm{~N}_{0} \mathrm{M}_{0}$ stage did not change over time (AAPC: $-3.15 \%, p=0.06$ ). Due to sample size limitations, ASR could not be computed for other stage in females.

\section{Discussion}

We hypothesized that important differences may exist in urethral cancer ASR in contemporary patients, according to gender, age, race, histological subtype, region and stage. We tested this hypothesis within the SEER database 2004-2016 and arrived at several noteworthy observations.

First, we corroborated an important difference in ASR, relative to the previous figures reported by Swartz et al. [1]. Overall, ASR in urethral cancer was $1.69 / 1,000,000$. 
After stratification according to patient sex, ASR was 2.70 vs. $0.55 / 1,000,000$ in males vs. females, respectively. Moreover, in temporal trend analyses, ASR decreased in both sexes at a similar rate. Although, the absolute ASR is different in contemporary urethral cancer patients, relative to more historic controls, our findings are comparable to Swartz et al., with respect to sex distribution [1]. Specifically, ASR was higher in males than in females. However, comparisons of absolute rates cannot be made, due to methodological and patient population differences.

Second, we identified important differences according to race, as well as patient sex. Specifically, stratification according to race differed between males and females. In consequence, sex-specific results focusing on race were reported. In males, highest ASR was recorded in African Americans, followed by Caucasians and Hispanics, in that order. The same relationship was recorded in females. However, in females, the absolute numbers were lower in African Americans and Caucasians than those reported in males. Finally, ASR could not be computed for Hispanic females due to insufficient numbers. Despite those differences, the temporal trends were highly comparable between males and females, in African American and Caucasian patient groups. Our findings are comparable to Swartz et al., who also reported higher historic incidence rates in African American males and females, relative to Caucasian males and females [1].

Third, we identified important differences according to histological subtypes, as well as according to patient sex. Specifically, stratification according to histological subtypes differed between males and females. In consequence, sex-specific results focusing on histological subtypes were reported. In males, highest incidence rates were recorded in urothelial histological subtype, followed by SCC and adenocarcinoma. In females, incidence rates were comparable between all histological subtype groups. In temporal trend analyses, in both males and females no ASR differences were recorded according to histological subtype. To the best of our knowledge, no contemporary study reported incidence rates according to histological subtype of urethral cancer. In consequence, our data cannot directly be compared to contemporary studies. However, our observations are comparable with previous reports, where urothelial histological subtype was predominant in male urethral cancer patients and were more equal distribution of histological subtype (urothelial, SCC, adenocarcinoma and other) was recorded in female urethral cancer patients [8, 9, 14-18].

Fourth, we tested for differences in ASR according to four SEER regions, namely Midwest, Northeast, South and West. It is of note that important sample size differences exist between those four regions. Specifically, Midwest included 205 observations vs. 901 in West vs. 481 in South vs. 320 in Northeast. Despite numeric and regional membership differences, we corroborated ASR regional differences. These were in agreement with regional differences described by Swartz et al. [1]. Neither Swartz et al. nor the current data can provide firm indications to explain those differences. Moreover, similar to the study by Swartz et al., we also observed the highest incidence of urethral cancer patients in the age category of patients $\geq 75$ years [1]. However, no significant changes were observed in the incidence of all age categories over time. These observations are noteworthy, since with demographic changes an increasing incidence in the oldest age category may have been expected.

Fifth, important differences in stage stratified analyses were recorded. Overall ASR was highest in $\mathrm{T}_{1} \mathrm{~N}_{0} \mathrm{M}_{0}$, followed by $\mathrm{T}_{3-4} \mathrm{~N}_{0} \mathrm{M}_{0}, \mathrm{~T}_{1-4} \mathrm{~N}_{1-2} \mathrm{M}_{0}, \mathrm{~T}_{1-4} \mathrm{~N}_{0-2} \mathrm{M}_{1}$ and $\mathrm{T}_{2} \mathrm{~N}_{0} \mathrm{M}_{0}$ stage. After stratification according to male sex, highest ASR was also reported in $T_{1} N_{0} M_{0}$ stage, followed by $T_{3-4} N_{0} M_{0}$. Due to limited sample size, incidence rates could not be computed in females. In consequence, the overall rates very closely approximated those recorded in males. In temporal trend analyses, T1N0M0 stage significantly decreased over time $(-3.00 \%, p=0.02)$ in favor of $\mathrm{T} 1-4 \mathrm{~N} 1-2 \mathrm{M} 0$ stage $(+2.11 \%, p=0.02)$. In temporal trend analyses that focused on males, the same pattern of stage distribution was observed. To the best of our knowledge, we are the first to report ASR according to stage at presentation in urethral cancer. In consequence, our data cannot be compared to previous investigations. Nonetheless, our findings require consideration in clinical practice, due to the increase in unfavorable stage $\mathrm{T}_{1-4} \mathrm{~N}_{1-2} \mathrm{M}_{0}$ rate.

Taken together, our results provided important observations about urethral cancer incidence and its trends over time. First, urethral cancer ASR is very low, relative to other urologic primaries [19-22]. Its ASR is highest in males, elderly patients, African Americans and in urothelial histological subtype. Most incident cases are stage $\mathrm{T}_{1} \mathrm{~N}_{0} \mathrm{M}_{0}$. However, over time, the importance of $\mathrm{T}_{1} \mathrm{~N}_{0} \mathrm{M}_{0}$ decreased in favor of $\mathrm{T}_{1-4} \mathrm{~N}_{1-2} \mathrm{M}_{0}$. This observation is worrisome and may be indicative in diagnostic delays.

Our work has limitations and should be interpreted in the context of its retrospective and population-based design. Second, our results relied on US population and may not be generalizable to other western countries. Third, our cohort relies on a small sample that resulted in lack of significant differences in some subgroup comparisons. Fourth, histologic diagnoses in the SEER database are derived from medical records, without central review. However, it should be emphasized that the SEER database is designed to providing proportional representation of the United States' population and only the National Cancer Data Base can provide a larger sample of urethral cancer patients, without providing cancer-specific mortality rates that are required in any cancer analysis. 
Author contributions All authors contributed to the study conception and design. Material preparation, data collection and analysis were performed by Mike Wenzel, Luigi Nocera, Claudia Collà Ruvulo, Christoph Würnschimmel and Zhe Tian. The first draft of the manuscript was written by Mike Wenzel and Pierre I Karakiewicz and all authors commented on previous versions of the manuscript. Especially Shahrokh F Shariat, Fred Saad, Alberto Briganti, Derya Tilki, Philipp Mandel, Andreas Becker, Luis A Kluth and Felix KH Chun supervised the work and reviewed and edited the manuscript. All authors read and approved the final manuscript.

Funding Open Access funding enabled and organized by Projekt DEAL. The authors have no relevant financial or non-financial interests to disclose.

Data availability All datasets generated for this study are included in the manuscript.

Code availability Software R statistics (version 3.6.1).

\section{Declarations}

Conflict of interest Not applicable.

Ethical approval All analyses and their reporting followed the SEER reporting guidelines. Due to the anonymously coded design of the SEER database, study-specific Institutional Review Board ethics approval was not required.

Consent to participate Not applicable.

Consent for publication Not applicable.

Open Access This article is licensed under a Creative Commons Attribution 4.0 International License, which permits use, sharing, adaptation, distribution and reproduction in any medium or format, as long as you give appropriate credit to the original author(s) and the source, provide a link to the Creative Commons licence, and indicate if changes were made. The images or other third party material in this article are included in the article's Creative Commons licence, unless indicated otherwise in a credit line to the material. If material is not included in the article's Creative Commons licence and your intended use is not permitted by statutory regulation or exceeds the permitted use, you will need to obtain permission directly from the copyright holder. To view a copy of this licence, visit http://creativecommons.org/licenses/by/4.0/.

\section{References}

1. Swartz MA, Porter MP, Lin DW, Weiss NS (2006) Incidence of primary urethral carcinoma in the United States. Urology 68(6):1164-1168. https://doi.org/10.1016/j.urology.2006.08.1057

2. Gakis G, Witjes JA, Compérat E et al (2013) EAU guidelines on primary urethral carcinoma. Eur Urol 64(5):823-830. https://doi. org/10.1016/j.eururo.2013.03.044

3. National Comprehensive Cancer Network. Bladder Cancer (Version 5.2020)

4. Sui W, RoyChoudhury A, Wenske S, Decastro GJ, McKiernan JM, Anderson CB (2017) Outcomes and prognostic factors of primary urethral cancer. Urology 100:180-186. https://doi.org/10.1016/j. urology.2016.09.042

5. Libby B, Chao D, Schneider BF (2010) Non-surgical treatment of primary female urethral cancer. Rare Tumors 2(3):e55. https:// doi.org/10.4081/rt.2010.e55
6. Wiener JS, Liu ET, Walther PJ (1992) Oncogenic human papillomavirus type 16 is associated with squamous cell cancer of the male urethra. Cancer Res 52(18):5018-5023

7. Sawczuk I, Acosta R, Grant D, White RD (1986) Post urethroplasty squamous cell carcinoma. N Y State J Med 86(5):261-263

8. Wenzel M, Nocera L, Collà Ruvolo C, et al. Sex-Related Differences Include Stage, Histology, and Survival in Urethral Cancer Patients. Clin Genitourin Cancer. Published online January 6, 2021. https://doi.org/10.1016/j.clgc.2020.12.001

9. Wenzel M, Deuker M, Nocera M, Collà Ruvulo C, Tian Z, Shariat SF (2021) Comparison between urothelial and non-urothelial urethral cancer. Front Oncol. https://doi.org/10.3389/fonc.2020. 629692

10. Wenzel M, Deuker M, Stolzenbach F, et al. The effect of race/ ethnicity on histological subtype distribution, stage at presentation and cancer specific survival in urethral cancer. Urol Oncol. Published online December 10, 2020. https://doi.org/10.1016/j. urolonc.2020.11.031

11. About the SEER Program. SEER. [cited 2020 June 20]. Available from https://seer.cancer.gov/about/overview.html.

12. Humphrey PA, Moch H, Cubilla AL, Ulbright TM, Reuter VE (2016) The 2016 WHO classification of tumours of the urinary system and male genital organs-part B: prostate and bladder tumours. Eur Urol 70(1):106-119. https://doi.org/10.1016/j. eururo.2016.02.028

13. Brierley, J.D., et al. TNM classification of malignant tumors. UICC International Union Against Cancer. 2017, Wiley/ Blackwell.

14. Champ CE, Hegarty SE, Shen X et al (2012) Prognostic factors and outcomes after definitive treatment of female urethral cancer: a population-based analysis. Urology 80(2):374-381. https://doi. org/10.1016/j.urology.2012.02.058

15. Rabbani F (2011) Prognostic factors in male urethral cancer. Cancer 117(11):2426-2434. https://doi.org/10.1002/cncr.25787

16. Aleksic I, Rais-Bahrami S, Daugherty M, Agarwal PK, Vourganti S, Bratslavsky G (2018) Primary urethral carcinoma: a surveillance, epidemiology, and end results data analysis identifying predictors of cancer-specific survival. Urol Ann 10(2):170-174. https://doi.org/10.4103/UA.UA_136_17

17. Derksen JW, Visser O, de la Rivière GB, Meuleman EJ, Heldeweg EA, Lagerveld BW (2013) Primary urethral carcinoma in females: an epidemiologic study on demographical factors, histological types, tumour stage and survival. World J Urol 31(1):147-153. https://doi.org/10.1007/s00345-012-0882-5

18. Wei Y, Wu Y-P, Xu N et al (2017) Sex-related differences in clinicopathological features and survival of patients with primary urethral carcinoma: a population-based study. OncoTargets Ther 10:3381-3389. https://doi.org/10.2147/OTT.S139252

19. Siegel RL, Miller KD, Jemal A (2019) Cancer statistics, 2019. CA Cancer J Clin 69(1):7-34. https://doi.org/10.3322/caac.21551

20. Gatta G, van der Zwan JM, Casali PG et al (2011) Rare cancers are not so rare: the rare cancer burden in Europe. Eur J Cancer Oxf Engl 47(17):2493-2511. https://doi.org/10.1016/j.ejca.2011.08.008

21. McCormick B, Dahmen A, Antar A, Baumgarten A, Dhillon J, Spiess PE (2017) Rare urologic tumors. Curr Opin Urol 27(1):6875. https://doi.org/10.1097/MOU.0000000000000356

22. Dell'Atti L, Galosi AB (2018) Female Urethra Adenocarcinoma. Clin Genitourin Cancer 16(2):e263-e267. https://doi.org/10. 1016/j.clgc.2017.10.006

Publisher's Note Springer Nature remains neutral with regard to jurisdictional claims in published maps and institutional affiliations. 